\title{
HACIA UNA EDUCACIÓN CON EQUIDAD
}

\author{
TOWARDS AN EQUITABLE EDUCATION
}

\author{
Sandra Emma Carmona Valdés*
}

\section{RESUMEN}

En la Cuarta Conferencia Mundial de la Mujer realizada en Beijing en 1995, el Gobierno de México se comprometió internacionalmente a garantizar a las mujeres el acceso de manera equitativa a las oportunidades sociales, económicas, políticas, laborales, educativas, culturales y de salud (Organización Naciones Unidas, 1995). El objetivo de este documento es analizar las políticas con perspectiva de género implementadas en México en el ámbito educativo con respecto a los lineamientos establecidos en la Cuarta Conferencia Mundial sobre la Mujer. La investigación documental utilizó el programa ATLAS.ti para sistematizar la información, cada voluntad política y/o acción positiva presentada es una respuesta específica a dos principales demandas expuestas en los lineamientos establecidos en la Plataforma de Acción de Beijing (acceso y permanencia de la mujer a la educación formal y formación con equidad de género) y, engloban el conjunto de acciones realizadas para lograr la equidad de género por parte de las distintas dependencias del Estado. Frente al compromiso ratificado internacionalmente para la igualdad en el acceso a las oportunidades educativas, y a la formación en género desde la educación formal se han realizado importantes avances; sin embargo, las inequidades persistentes requieren de mayores esfuerzos para establecer oportunidades equitativas para hombres y mujeres que permita alcanzar una sociedad más justa y equitativa.

Palabras clave: Equidad, Educación, Perspectiva de género, Políticas Públicas.

\section{ABSTRACT}

At the Fourth World Conference on Women held in Beijing in 1995, the Government of Mexico is internationally committed to ensuring women's access to equitable social opportunities, economic, political, labor, educational, cultural and health (UN Organization, 1995). The aim of this paper is to analyze gender policies implemented in Mexico in education with respect to the guidelines established in the Fourth World Conference on Women. The documentary research used ATLAS.ti to systematize information, each political will and positive action filed is a specific response to two main demands set out in the guidelines established in the Beijing Platform for Action (access and retention of women formal education and training in gender equity) and encompass the set of actions to achieve gender equality by the various agencies of the State. Against compromise ratified internationally for equal access to educational opportunities, and gender training from formal education have made significant

Fecha de recepción: Febrero 06 de 2015 / Fecha de aceptación: Marzo 20 de 2015

Tipología: Artículo de Investigación Científica y Tecnológica

Para citar este artículo: Carmona, V. S. (2015). Hacia una educación con equidad. Praxis. Vol. 11, 8 - 18

*Doctora en Filosofía con Orientación en Trabajo Social y Políticas Comparadas de Bienestar Social por la Universidad Autónoma de Nuevo León, México. Miembro del Sistema Nacional de Investigadores. Profesora Investigadora en la Facultad de Trabajo Social y Desarrollo Humano de la Universidad Autónoma de Nuevo León. en el área de posgrado, pertenece al Cuerpo Académico consolidado de Políticas Sociales Sectoriales. Su línea de investigación son Adultos Mayores, Políticas Públicas y Género. México. E-mail: carmona.uanl@gmail.com 
progress; however, persistent inequalities require greater efforts to establish equitable opportunities for men and women that would achieve a more just and equitable society.

Keywords: Equity, Education, Gender Perspective, Public Policy.

\section{INTRODUCCIÓN}

$\mathrm{E}$ l compromiso de trabajar en pro de la igualdad entre hombres y mujeres a nivel internacional surge en 1945 , buscando igualar los derechos jurídicos y civiles de hombres y mujeres. No obstante, la igualdad jurídica no representó un mecanismo suficiente para garantizar la plena igualdad ni tampoco para alcanzar la plena participación de la mujer en la vida social, política, económica y cultural. Fue hasta 1975, en la Asamblea General de las Naciones Unidas que se declaró el Año Internacional de la Mujer y se decidió realizar en México la Primera Conferencia Mundial de la Mujer, para plantear estrategias comunes que permitieran avanzar en beneficio de la igualdad de derechos y participación de la mujer. Como una respuesta a dicho compromiso, la Asamblea proclamó al período entre 1976 y 1985 como el Decenio de las Naciones Unidas para la Mujer, con la intención de promover el avance de las mujeres a escala mundial en tres dimensiones: la igualdad plena de género y la eliminación de la discriminación por motivos de género, la integración y plena participación de las mujeres en el desarrollo, y la contribución activa de las mujeres al fortalecimiento de la paz mundial (Organización Naciones Unidas, 2000).

En el año 1979, se aprobó La Convención sobre la eliminación de todas las formas de discriminación contra la Mujer, la cual, constituyó el instrumento legal más importante para la promoción de la igualdad de derecho de la mujer en todas las esferas sociales, dando prioridad al acceso al empleo, a la educación y a las actividades económicas sin discriminación (Organización Naciones Unidas, 1979). Al año siguiente, se realizó la Segunda Conferencia Mundial de la Mujer realizada en Copenhague, con la finalidad de evaluar el Plan de Acción de
1975 según los avances obtenidos con respecto a las metas planteadas. A pesar de los progresos alcanzados se observó que todavía persistían dificultades entre los derechos garantizados y la capacidad de la mujer para ejercer dichos derechos. Para modificar tal situación se estableció el Programa de Acción de Copenhague, el cual, priorizó la educación, el empleo y la salud como áreas de atención buscando conseguir las metas de Igualdad, Desarrollo y Paz (Organización Naciones Unidas, 2000).

La Tercera Conferencia Mundial sobre la Mujer realizada en Nairobi en 1985, convocó a los países miembros a evaluar los avances del Decenio de las Naciones Unidas para la Mujer. La evaluación reflejó que la igualdad jurídica y social de la mujer había favorecido solamente a una pequeña minoría. La comprensión de esa situación obligó a adoptar un nuevo enfoque para superar los obstáculos y alcanzar la igualdad de la mujer plasmándose en el Programa de Acción de Nairobi, en el cual, centró la atención en las medidas constitucionales y jurídicas, en la igualdad en la toma de decisiones y en la participación social y política de la mujer (Organización Naciones Unidas, 2000). Posteriormente en 1995 se celebró la Cuarta Conferencia Mundial sobre la Mujer en Beijing, en la cual se reconoció la necesidad de integrar la perspectiva de género en las políticas y en la administración pública, lo cual, permitiría fortalecer plenamente el papel activo de la mujer en igualdad en todas las áreas y etapas de la vida. A partir de ello, los gobiernos se comprometieron a transversalizar la perspectiva de género en todas sus instituciones, políticas, procesos de planificación y de adopción de (Organización Naciones Unidas, 2000).

El objetivo de este trabajo es analizar las políticas con perspectiva de género implementadas en México en el ámbito educativo, con relación 
a los lineamientos establecidos en la Cuarta Conferencia Mundial sobre la Mujer plasmados en la Plataforma de Acción de Beijing. Considerando la educación como un punto de partida para lograr la equidad entre hombres y mujeres al permitir el desarrollo pleno del potencial de la mujer y como un instrumento fundamental para el logro de los objetivos de Igualdad, Desarrollo y Paz. Sin embargo, hoy en día hombres y mujeres difieren en la manera de educarse, en la forma de relacionarse, en los estilos de vida, y en las posibilidades de acceso a los bienes y servicios. Estas diferencias que separan a hombres y mujeres se basan en lo que se define como la construcción cultural de género, la cual llega a convertirse en un hecho social de tanta fuerza que determina la manera en que hombres y mujeres vivirán (Lagarde, 1997).

La construcción cultural de género integra el conjunto de creencias, valores, actividades, espacios, actitudes y rasgos de personalidad que reglamentan y condicionan el comportamiento de las personas, atribuyendo características distintas para cada sexo acerca de lo que es "masculino" y lo que es "femenino". De tal suerte que se establecen socialmente modelos, prácticas, ideas estereotipadas, discursos y representaciones sociales para mujeres y hombres, los cuales son promovidos y mantenidos por instituciones sociales como la escuela, la iglesia y el Estado (Burín \& Meler, 1998). En este sentido, se parte de la premisa de que a través de la educación formal se transmiten imágenes femeniles y varoniles diferenciadas permeando el acceso a la educación, la actividad académica, los procesos socializadores, las normas educativas, los aspectos organizativos, las actividades lúdicas, las actitudes y las expectativas del personal hacia el alumnado, entre otras.

La importancia de educar a hombres y mujeres de diferente manera establece formas de vida dicotómicas, debido a que los patrones de comportamiento esperado son extremadamente diferenciados y opuestos entre sí (Martín, 1985). Este contraste trasciende no en la diferenciación en sí, sino en que dichas imágenes acerca de la mujer, la llevan a asumir un rol inferior dentro de la sociedad que desvaloriza sus capacidades físicas, intelectuales y creativas; así como también la encasilla a un papel de reproductora y socializadora. Por lo que, a lo largo de la historia, esta situación ha generado prejuicios, discriminación, exclusión y violencia hacia la mujer.

Un primer acercamiento hacia la igualdad representaría el acceso pleno y equitativo a la educación en condiciones de igualdad para hombres y mujeres (Instituto Nacional de las Mujeres, 2008). Anteriormente, la mujer asistía a la escuela en una proporción inferior a la de los varones, a quienes se les daba prioridad de participación debido a que ellos representaban el sustento económico del hogar, es decir, era importante que se educasen para estar mejor preparados para proveer y mantener a una familia. En cambio, no se consideraba necesario la participación de la mujer en la educación formal y menos en la educación superior debido a que la principal función de la mujer era el cuidado del hogar y a las actividades reproductivas. Esta situación se puede observar en el porcentaje femenino de estudiantes que asistía en nivel superior en 1969, apenas alcanzaba el $17.3 \%$ (Galeana, 1994).

Esta ausencia de participación en la educación formal constituía uno de los ámbitos privilegiados de reproducción de las desigualdades de género en el fortalecimiento de la división sexual del trabajo. De esta forma, los varones eran quienes accedían a los estudios superiores como parte de su integración exitosa a la esfera pública $\mathrm{y}$ al reconocimiento social, mientras las mujeres eran invisibilizadas en la esfera privada y asignadas a las tareas propias de la reproducción y cuidados de la familia y el hogar (Papadópulos \& Radakovich, 2003). No obstante, en las últimas décadas hemos podido observar un incremento significativo en la matrícula escolar femenina, cifras oficiales registran para el año 2010 por cada 10 hombres hay siete mujeres en educación superior (Instituto Nacional de Estadística Geografía e Informática, 2010).

El proceso de incorporación de la mujer en la educación superior en sus inicios estuvo caracterizado principalmente por áreas profesionales como la enfermería, el trabajo social, la educación, la nutrición, las humanidades y las ciencias 
sociales, entre otras, representando el ámbito profesional como una extensión de las "roles femeninos" en la esfera pública. Así lo señalan Papadópulos y Radakovich (2003), los espacios de concentración de la matrícula femenina en la educación superior agrupaban carreras o áreas de estudio consideradas propiamente "femeninas” debido a que el desempeño de las mismas estaba asociado a la extensión de los papeles tradicionales de la mujer en el espacio privado, tales como el cuidado y atención de personas dependientes y tareas relacionadas con la alimentación, vestimenta, educación básica, salud primaria, relaciones públicas, entre otros.

En los últimos treinta años, es cada vez más frecuente la participación de la mujer en áreas "tradicionalmente masculinas" y no solamente las delimitadas por el género. Aunque todavía persiste una distribución desigual en función del sexo, aunado a que las áreas tecnológicas y las ciencias básicas continúan siendo percibidas como "espacios masculinos" y concentran mayores porcentajes de matriculación masculina. Por lo que, el proceso de superar las barreras culturales de inserción de varones y mujeres ha sido paulatino en comparación con el acceso masivo de la mujer a la educación superior.

El segundo acercamiento hacia la igualdad representa la formación con equidad de género, la cual concibe a la educación formal de manera integral, en la que engloba la transmisión de disciplinas científicas, competencias laborales y acervos culturales que permiten formar ciudadanos libres y capaces para ejercer sus libertades fundamentales y exigir el cumplimiento de sus derechos en una sociedad democrática (Instituto Nacional de las Mujeres, 2008). Por lo tanto, la formación con equidad de género debe ir encaminada al desarrollo físico, psicológico y social, trasmitiendo valores y patrones no sexistas en sus educandos; en donde se debe evitar por medio del lenguaje, los contenidos, los juegos, el trato, los materiales didácticos y otras prácticas pedagógicas se refuercen los estereotipos de género.

Sin embargo, hombres y mujeres se educan para ser diferentes desde las aulas, es decir, en los varones se observa mayor promoción en actividades relacionadas con las matemáticas, los procesos de abstracción e investigación; en las actividades cívicas, se les elige para representar a la escuela como abanderados u oradores, a ellos se les otorga el predominio de la presencia pública. Las niñas, en cambio, se les impulsan a ser detallistas, a cuidar la forma más que el contenido y a atender la limpieza del ambiente escolar -suelen ayudar a limpiar el pizarrón, las mesas, lavar los pinceles, recoger la basura, etc.-; en las actividades extracurriculares las niñas adornan el espacio escolar, son ellas las que cantan o bailan (Instituto Nacional de las Mujeres, 2002). Lovering y Sierra (2005) establecen que dentro de los programas educativos, los libros de texto y el material didáctico, se resaltan las actividades realizadas por hombres, mientras se subestima, se omite o se invisibilida a las mujeres y niñas.

De igual forma sucede con los procesos socializadores, las expectativas de comportamiento para los varones son proyectados como seres cuyo deber es actuar, accionar y transformar el mundo (Lagarde, 1997), por lo que se espera y se promueve que los niños demanden mayor atención por parte de las educadoras, reclamen ser escuchados y expresen abiertamente su enojo cuando ven afectados sus intereses, se observa que son más inquietos, corren y gritan con mayor soltura. A diferencia de las niñas, las cuales se espera que sean tiernas, altruistas y serviciales, se les exige ser "bien portadas", reciben más observaciones y reprobación ante conductas irruptivas, por lo que, se muestran más calladas, aprenden a esperar su turno y a guardar silencio. Las conductas de violencia e intolerancia, si bien se sancionan, en los niños son aceptadas y menos castigadas, ya que en opinión de algunas docentes estas conductas son parte de su "naturaleza"; en cambio, a las niñas se les recrimina si no se comportan de manera más sutil y dócil, según el esquema preestablecido de lo que consideran un comportamiento femenino (Instituto Nacional de las Mujeres, 2002).

Asimismo, las expectativas de los y las docentes acerca de lo que desean que sus alumnas y alumnos sean en el presente y en el futuro orienta de 
manera diferencial a niños y niñas a través del trato, el lenguaje, los gestos, el tono de la voz, la frecuencia y duración de la atención, el tipo de preguntas y de respuestas, los chistes, las caricaturas y el sarcasmo empleado por parte del profesorado, esta diferenciación establece distinciones entre hombres y mujeres. Spender (1986 citado por Acker 2000) refiere que la escuela contribuye a la lógica del dominio del hombre a través de los procesos que silencian a las mujeres y permiten a los hombres dominar los espacios y tomar decisiones; y a la función del lenguaje en el control que ejerce sobre la conceptualización de la mujer y del mundo.

La construcción cultural de género se reproduce también en las actividades lúdicas como en las canciones y en los cuentos, dentro de las cuales se reflejan con claridad las ideas preconcebidas y las representaciones sociales que reproducen los roles estereotipados de género: "La rata vieja que no sabe planchar", "la mamá que lava, plancha, hace la comida y va por sus hijas e hijos a la escuela", "el cochecito que compró papá para llevar a su familia a la ciudad". En los cuentos que hacen alusión a las princesas y a las bellas damas siembran el ideal para alcanzar para las mujeres. A diferencia de las imágenes varoniles propuestas para los niños, ellos "dominan el universo", "conquistan la tierra y en el espacio" y "salvan a las princesas" (Instituto Nacional de las Mujeres, 2002). Niños y niñas adquieren y utilizan dichos estereotipos de la misma manera que adquieren y utilizan otras ideas y valores, lo cual, les permite integrase y adaptarse socialmente a su grupo. La trascendencia de estos estereotipos y sus implicaciones radica en que desde la educación formal se imponen maneras de ver la vida y se alaban vivencias que mantienen -en diversos grados y formas- las formas de organización social tradicional (Tuirán \& Salles, 1998).

Para frenar la reproducción de la construcción cultural de género desde la educación formal y evitar la transmisión a las nuevas generaciones, el gobierno de México se comprometió internacionalmente a integrar políticas educativas con perspectiva de género. A 20 años de dicho compromiso, se busca analizar la voluntad política y las acciones positivas implementadas en el ámbito educativo para evitar que continúe ocurriendo la educación diferencial entre hombres y mujeres desde las aulas.

\section{METODOLOGÍA}

El corpus de la investigación estuvo conformado por la Ley General de Acceso a las Mujeres a una Vida Libre de Violencia, el Plan Nacional de Desarrollo 2007-2012, el Programa Sectorial de Educación 2007-2012, el Programa Nacional de Cultura 2007-2012, el Programa Nacional para la Igualdad de Oportunidades y no Discriminación contra las Mujeres 2009-2012, el Programa de Becas para Adolescentes Embarazadas, el Programa de Becas Fundación Azteca, el Programa de Capacitación al Magisterio para Prevenir la Violencia contra las Mujeres, el Programa de Formación Docente de Educación Media Superior, el Programa Nacional de Becas para la Educación Superior, el Programa Nacional de Becas para la Retención de Estudiantes de Educación Media Superior, el Programa de Estancias y Guarderías Infantiles para Madres Trabajadoras y el Programa Oportunidades, los cuales atienden las demandas planteadas en la Cuarta Plataforma de Acción en el tema de educación plasmadas en la Plataforma de Acción 1995. La voluntad política nacional, el marco jurídico que sustenta normativamente los compromisos adquiridos y las acciones emprendidas que dan respuesta a dichos compromisos presentadas a continuación son una respuesta específica a dos principales demandas (acceso y la permanencia de la mujer a la educación formal y formación con equidad de género) expuesta en dichos lineamientos y, engloban el conjunto de acciones realizadas para lograr la equidad de género por parte de las distintas dependencias del Estado. La investigación documental utilizó el programa ATLAS.ti para sistematizar la información. 


\section{RESULTADOS}

Para garantizar la equidad entre hombres y mujeres, el Gobierno de México incorporó la perspectiva de género en las políticas públicas, lo cual, representó un importante progreso en materia de equidad que permitió reconocer la existencia de decisiones políticas no intencionales, que impactan de manera diferencial debido a que las condiciones de inicio entre hombres y mujeres son desiguales, aun cuando estas consecuencias no estén previstas ni se deseen (Astelarra, 2004); e implicó la delimitación de necesidades específicas de atención para hombres y mujeres por parte del Estado. Posteriormente, se incluyó el concepto de equidad de género en la agenda política y la igualdad de oportunidades entre los grupos sociales y entre los géneros, para asegurar que todos los ciudadanos tengan las mismas oportunidades en los diferentes ámbitos. En relación al ámbito educativo, el Gobierno de México se comprometió a lograr la equidad educativa en el acceso y la permanencia de la mujer a la educación formal. Al ofrecer a la población femenina el acceso pleno y equitativo a la educación en condiciones de igualdad se obtienen innumerables beneficios tanto para la población en general como para la población femenina en particular. Para ello, se requiere eliminar cualquier tipo de discriminación por motivos de género y garantizar la igualdad de oportunidades educativas (Presidencia de la República de México, 2007). Esta voluntad política se encuentra amparada normativamente en la Ley General de Acceso de las Mujeres a una Vida Libre de Violencia, la cual, instaura la implementación de políticas educativas con principios de igualdad, equidad, no discriminación y respeto a los Derechos Humanos (Cámara de Diputados, 2009).

Las estrategias de acción que dan respuesta a este compromiso se orientan a la coordinación institucional entre la Secretaría de Educación Pública, las Secretarías de Educación y/o sus homólogas en las entidades federativas, el Consejo Nacional de Fomento Educativo y la corresponsabilidad de los tres órdenes de gobierno (Secretaría de Educación Pública, 2007e); para reducir las desigualdades entre los géneros, entre las regiones y los grupos sociales. Además de apoyar de manera económica a los grupos que se encuentran en desventaja a través de becas económicas, entre los programas que ofrecen becas se encuentran:

El Programa Oportunidades orienta sus acciones para apoyar la inscripción, la permanencia y la asistencia regular a la escuela, a los hijos/as de las familias beneficiarias, a través de becas educativas y apoyos para la adquisición de útiles escolares. Las becas que este programa otorga van dirigidas a niños, niñas y jóvenes menores de 18 años, que estén inscritos en grados escolares comprendidos entre tercero de primaria y tercero de secundaria en escuelas de modalidad escolarizada; consisten en apoyos monetarios que se entregan bimestralmente durante los diez meses del ciclo escolar, es decir, de Septiembre a Junio (Secretaría de Desarrollo Social, 2009). El Programa de Becas Fundación Azteca ofrece la "Beca Azteca" que es un programa anual de becas al 100\%, el cual brinda a los jóvenes seleccionados (ambos sexos), la oportunidad de continuar con sus estudios totalmente becados (Secretaría de Educación Pública, 2007b).

Para garantizar la permanencia de las adolescentes en el ámbito educativo es necesario considerar el principal motivo por el cual abandona la escuela: el embarazo adolescente. Esta situación presenta diversas problemáticas tanto de salud, económicas, familiares, rechazo y discriminación social, ambiente escolar hostil como nuevas responsabilidades familiares, que dan lugar a que la mayoría de las jóvenes embarazadas se ven obligadas a abandonar su educación. En este sentido, el embarazo adolescente constituye un obstáculo para la continuación y finalización de la preparación académica. Para evitar la deserción escolar por este motivo, las estrategias se orientan al apoyo económico de madres jóvenes y jóvenes embarazadas mediante el Programa de Becas para Adolescentes Embarazadas (Secretaría de Educación Pública, 2007a) y el Programa Oportunidades (Secretaría de Desarrollo Social, 2009). Ambos programas otorgan un apoyo económico de \$650.00 mensual durante 10 meses, lo cual le permitirá continuar con sus estudios hasta su término. Asimismo, se establece la coordinación con el Programa de 
Estancias y Guarderías Infantiles para Madres Trabajadoras para ampliar su cobertura e incluir a las madres jóvenes (Secretaría de Desarrollo Social, 2009).

El acceso de la mujer a la Educación Superior busca aumentar la cobertura dando prioridad a las entidades federativas con mayor rezago y demanda social. La estrategia de acción consiste en incrementar la cobertura, la diversificación de la oferta educativa y el apoyo económico para que pueda continuar su educación media superior, a través de cuatro programas: a) el Programa Nacional de Becas para la Educación Superior dirigido a hombres y mujeres, su atención no es exclusiva para mujeres, pero permite asegurar el acceso de la mujer a la enseñanza superior (Secretaría de Educación Pública, 2007f); b) el Programa Nacional de Becas para la Retención de Estudiantes de Educación Media Superior apoya económicamente a las alumnas(os) para que continúen con sus estudios para evitar la deserción. Las mujeres reciben un monto mayor (Secretaría de Educación Pública, 2007g); c) el Programa Oportunidades otorga becas de educación media superior a jóvenes de entre 14 y 21 años en modalidad escolarizada. Su monto es creciente a medida que el grado que se cursa sea más alto. En secundaria y en educación media superior las becas para las mujeres son superiores a las de los hombres, debido a que las mujeres por diversos motivos tienden a abandonar sus estudios en mayor proporción y en edades más tempranas que los hombres (Secretaría de Desarrollo Social, 2009); d) el Programa de Becas Fundación Azteca (Secretaría de Educación Pública, 2007b).

La segunda demanda para lograr la equidad educativa consiste en la formación con equidad de género (Naciones Unidas, 1995). Esta demanda se fundamenta normativamente en la Ley General de Acceso a las Mujeres a una Vida Libre de Violencia, con la finalidad de transformar los modelos socioculturales que toleran la violencia al reeducar libre de estereotipos y discriminación (Cámara de Diputados, 2009). La voluntad política consiste en difundir la importancia de la igualdad entre mujeres y hombres, promoviendo la eliminación de estereotipos establecidos en función del género, a través de acciones orientadas a crear una nueva cultura de valor igual para mujeres y hombres (Presidencia de la República de México, 2007). La estrategia definida es la institucionalización de la perspectiva de género en las políticas educativas para lograr la igualdad entre hombres y mujeres.

Las líneas de acción formuladas planteadas en el Programa Nacional para la Igualdad de Oportunidades y no Discriminación contra las Mujeres 2009-2012 están encaminadas para incidir en tres ámbitos: el primero consiste en la modificación de los patrones socioculturales de conducta de hombres y mujeres, a fin de contrarrestar costumbres y estereotipos que se traducen en violencia contra las mujeres y promover una cultura de respeto, convivencia y tolerancia familiar (Instituto Nacional de las Mujeres, 2008). Las acciones se centran en la difusión y divulgación sobre la importancia de la igualdad entre mujeres y hombres.

El segundo ámbito incluye la modificación en los programas educativos, donde se incorporen programas educativos que incluyan patrones de conducta social y cultural equitativos y el respeto a los Derechos Humanos de las mujeres, evitando los prejuicios, la idea de la inferioridad o superioridad de uno de los sexos y las funciones estereotipadas asignadas a las mujeres y a los hombres. Como acciones directas se eliminarán los programas educativos y materiales que hagan apología de la violencia contra las mujeres o contribuyan a la promoción de estereotipos que discriminen y fomenten la desigualdad entre mujeres y hombres; se analizarán y revisarán los contenidos educativos transmitidos en relación a la reproducción de estereotipos, lenguaje sexista, obstrucción de participación de hombres y mujeres, prácticas violentas entre estudiantes o entre docentes en los planes educativos, los contenidos curriculares, los libros de texto y materiales interactivos y por último se incluirán los valores civiles y éticos como la tolerancia, la solidaridad, el respeto a las diferencias, defensa de los Derechos Humanos dirigidos a alumnos, maestros y padres de familia (Secretaría de Educación Pública, 2007e). 
El tercer ámbito de intervención se orienta a la formación del personal docente en perspectiva de género. El personal docente representa una figura esencial en la formación educativa y en el desarrollo de la dinámica escolar; su visión del mundo y de la sociedad influye inevitablemente en los alumnos. El Programa de Formación Docente de Educación Media Superior plantea el objetivo de formar, actualizar, y capacitar a los docentes de los planteles de educación media superior (Secretaría de Educación Pública, 2007d). El organismo encargado de la actualización y capacitación en Derechos Humanos, equidad y perspectiva de género es la Coordinación General de Actualización y Capacitación para Maestros en Servicio, a través del Programa de Capacitación al Magisterio para Prevenir la Violencia contra las Mujeres (Secretaría de Educación Pública, 2007c). Asimismo, el Consejo Nacional para la Cultura y las Artes ofrece a los docentes actualización en Derechos Humanos, los derechos y responsabilidades del niño, el género y equidad, mediante diplomados, cursos talleres, ciclos de conferencias, con la participación de otras instituciones (Consejo Nacional para la Cultura y las Artes, 2007).

\section{CONCLUSIONES}

Los actuales esfuerzos para aumentar la equidad en la educación en México se centran en facilitar el acceso para reducir las brechas educativas asociadas a las diferencias en el sexo, el estrato socioeconómico, en el ámbito rural/urbano y en los diversos grupos de población. Se parte de la premisa que la desigualdad educativa restringe el acceso a las oportunidades, lo cual, dificulta la capacidad de vivir y convivir en sociedad. Para que las estrategias de acción sean pertinentes en reducir la desigualdad y la discriminación educativa, las acciones deben orientarse para compensar esta desigualdad a través de diferentes mecanismos. Los mecanismos propuestos para el acceso y la permanencia de la mujer a la educación formal se centran principalmente en el apoyo económico (becas) y la ampliación de la cobertura mediante el uso de tecnologías -aulas virtuales-. En el discurso existe la voluntad política de brindar el acceso a la educación ampliando la cobertura y estableciendo el respaldo de becas para la permanencia escolar amparadas normativamente; por lo que, la voluntad política es congruente con las estrategias de intervención para el logro de la equidad educativa. Sin embargo, todavía queda mucho camino por recorrer para eliminar las inequidades persistentes en la relación a los niños y las niñas urbano/rurales.

A pesar de los esfuerzos que se han realizado para implantar mayor igualdad en el acceso a la educación en las áreas rurales se observa que la calidad en la educación sigue siendo menor que en las áreas urbanas, además de ser escaso el equipamiento de aulas y escuelas. Una enorme dificultad que enfrenta la educación a distancia (tecnología educativa, aulas virtuales) es que está en constante riesgo de robo y de complicaciones en su funcionamiento; por lo que, se considera necesario que el acceso equitativo a la educación se refleje en el alumnado a través de calidad en su formación, mayor asistencia, permanencia y finalización de los estudios.

En relación a la apertura de nuevos espacios y/o ámbitos en la educación y a la integración de las mujeres a profesiones afines a las ciencias exactas y tecnológicas se han obtenido resultados positivos. Desde hace algunos años algunas mujeres se han integrado a éstas áreas demostrando sus capacidades y conocimientos con éxito, en este sentido, existe el acceso; sin embargo, todavía se observa que las mujeres continúan eligiendo a nivel profesional carreras donde tradicionalmente han sido ocupadas por la mujer, dada la falta de acciones positivas que orienten la gama de posibilidades profesionales no tradicionales para las mujeres y los hombres. Dicho propósito se integra en el discurso pero no se plasma en ninguna línea de acción.

En cuanto a la formación con equidad de género, particularmente en la modificación de programas y materiales educativos, se observan esfuerzos importantes para integrar una mayor presencia de la mujer en los libros de texto y en la participación de las actividades educativas; sin embargo, no se ha dado énfasis en la modificación de los roles tradicionales de género que permitan lograr una visión de responsabilidad familiar compartida entre los géneros. Todavía aparecen imágenes 
femeninas estereotipadas desempeñando roles tradicionales en espacios privados y a la inversa, imágenes masculinas estereotipadas desempeñando roles tradicionales en espacios públicos. Se hace necesaria la integración de programas educativos con contenidos temáticos equitativos entre hombres y mujeres; si bien es importante reconocer que se han eliminado materiales educativos que justifican la violencia y contribuyen a la promoción de estereotipos tradicionales y se han realizado acciones positivas para transformar la figura tradicional de niñas, adolescentes, mujeres y hombres a imágenes equilibradas; todavía aparecen una enorme cantidad de imágenes y roles de género tradicionales, razón por la cual se requiere analizar minuciosamente los contenidos educativos desde la perspectiva de género en relación a la reproducción de estereotipos y al lenguaje sexista, en los planes educativos, los contenidos curriculares y los libros de texto para realizar los cambios pertinentes.

Con respecto a la formación docente, la voluntad política es congruente con las estrategias de acción implementadas, y los organismos que se encargan de ejecutarlas tienen sus funciones claramente establecidas y sus contenidos determinados (educación y cultura, Derechos Humanos, derechos y responsabilidades del niño, género y equidad) para el logro de los objetivos. Considerando la evaluación de la voluntad política y las estrategias de acción establecidas podríamos considerar un logro significativo en el camino de la equidad. Sin embargo, si reflexionamos el impacto de dichas acciones en las aulas, la evaluación se encuentra lejos de alcanzar el objetivo, ya que todavía encontramos docentes desempeñando prácticas diferenciadoras entre niños y niñas dentro de las aulas.

Para concluir, el Gobierno de México se comprometió internacionalmente a realizar acciones para lograr el acceso a la educación y a la formación con equidad de género, ratificando su compromiso con los acuerdos pactados en la Cuarta Conferencia Mundial sobre la Mujer. En el discurso existe la voluntad política de brindar el acceso a la educación, ampliando la cobertura y estableciendo el respaldo de becas para la permanencia escolar; e incorporando contenidos educativos que modifiquen los modelos de conducta social y cultural que generan prejuicios, violencia, discriminación, la idea de la inferioridad o superioridad de uno de los sexos y las funciones estereotipadas asignadas a las mujeres y a los hombres desde la educación formal. Por lo que, la voluntad política es congruente con las estrategias de intervención para el logro de la equidad educativa.

Las políticas de equidad de género e igualdad de oportunidades instauradas en el marco legal, constituyen los principales ejes en el Plan Nacional de Desarrollo (Presidencia de la República de México, 2007), sin embargo, este proceso requiere voluntad, estrategias y acciones directas más puntuales, ya que, la sola voluntad política no se traduce en cambios visibles que permitan transformar la realidad cotidiana de las mujeres (Astelarra, 2004). Para avanzar en la equidad de género en la educación sería necesario eliminar las diferencias innecesarias, eludibles e injustas entre hombres y mujeres. Cuando las políticas incorporan en el discurso la perspectiva de género pero en las estrategias de intervención integran parcialmente la perspectiva de género desde el diseño, la implementación, el financiamiento y monitoreo se reduce su beneficio. En este sentido, resulta pertinente constituir dicha perspectiva como parte integral de los objetivos, las metas, estrategias, los presupuestos, la agenda política, etcétera; por lo que, todavía queda mucho camino por recorrer para eliminar las inequidades educativas persistentes entre los sexos, en la relación de niños y niñas urbano/rurales y en relación a la formación con equidad de género.

Las políticas educativas con perspectiva de género enfrentan un gran desafío ya que su intervención debe encaminarse a romper con paradigmas tradicionales que conceptualizan a la mujer con una identidad femenina, realizando actividades y actuando en espacios sociales femeninos; situación inversa con los hombres. Cuando las políticas educativas no abordan la equidad de género -en esas tres áreas de expresión-, los cambios pueden producirse de manera paulatina en alguno de los niveles, pero la dicotomía se vuelve a producir (Astelarra, 2004), por 
lo que se avanza en una área y se retrocede en otra. Así, la incorporación de la perspectiva de género en las políticas educativas tiene efectos parciales en el camino hacia la equidad. Frente al compromiso establecido internacionalmente para la igualdad en el acceso a las oportunidades educativas, y a la formación en género desde la educación formal es importante reconocer los avances alcanzados; sin embargo, las inequidades persistentes requieren aún mayores esfuerzos para establecer oportunidades equitativas para hombres y mujeres que permita alcanzar una sociedad más justa y equitativa.

Al Fondo sectorial INMUJERES-CONACYT por el apoyo económico otorgado que permitió el desarrollo de la investigación "Evaluación de la Transversalidad de Género en la Política Pública”, la cual, participó en la convocatoria S0005-2008-1. Modalidad de investigación aplicada A1.

\section{REFERENCIAS BIBLIOGRÁFICAS}

Acker, S. (2000). Género y Educación. Madrid: Editorial Narcea S.A.

Astelarra, J. (2004). Políticas de género en la Unión Europea y algunos apuntes sobre América Latina. Santiago de Chile: CEPAL. Serie Mujer y Desarrollo.

Burín, M., \& Meler, I. (2001). Género y familia: poder, amor y sexualidad en la construcción de la subjetividad. Buenos Aires: Paidós.

Cámara de Diputados. (2009). Ley General de Acceso a las Mujeres a una Vida Libre de Violencia (Última Reforma DOF 02-04-2014). Recuperado de http://www.diputados.gob.mx/LeyesBiblio/pdf/ LGAMVLV.pdf

Consejo Nacional para la Cultura y las Artes. (2007). Programa Nacional de Cultura 2007-2012. (Primera edición 2007). Recuperado de http://www.conaculta.gob.mx/recursos/acerca_de/pnc2007_20121.pdf

Galeana, P. (1994). La Mujer en el México de transición. México: Universidad Nacional Autónoma de México.

Instituto Nacional de Estadística Geografía e Informática. (2010). Censo general de población y vivienda 2010. Tabulados básicos. Estados Unidos Mexicanos. Tomo II. Aguascalientes: Instituto Nacional de Estadística, Geografía e Informática.
Instituto Nacional de las Mujeres. (2002). El enfoque de género, una perspectiva necesaria en la reforma curricular de la educación inicial y preescolar (Primera reimpresión: marzo de 2004). Recuperado de http://cedoc.inmujeres.gob.mx/documentos_ download/100606.pdf

(2008). Programa Nacional para la Igualdad de Oportunidades y no Discriminación contra las Mujeres 2009-2012: Pro equidad 2009-2012 (DOF Decreto por el que se aprueba el Programa Nacional para la Igualdad entre Mujeres y Hombres 20092012). Recuperado de http://cedoc.inmujeres.gob. $\mathrm{mx} /$ documentos_download/100919.pdf

Lagarde, M. (1997). Género y feminismo. Desarrollo humano y democracia. Madrid: Horas y Horas. Segunda edición.

Lovering, D., \& Sierra G. (2005). El currículo oculto del género. Guadalajara: Centro de Investigación y Estudios de Género ITESO.

Martín, I. (1985). Acción e ideología: Psicología social desde Centroamérica. El Salvador: Editorial UCA.

Organización Naciones Unidas. (1979). Convención sobre la Eliminación de todas las formas de Discriminación contra la Mujer. Recuperado www.un.org/womenwatch/daw/csw/.../SP-CSWbackgrounder.pdf

(2000). Período extraordinario de sesiones de la Asamblea General de las Naciones Unidas para examinar la Plataforma de Acción de Beijing. Recuperado http://www.un.org/spanish/conferences/Beijing/Mujer2011.htm.

Presidencia de la República. (2007). Plan Nacional de Desarrollo 2007-2012 (DOF: 31/05/2007). Recuperado http://pnd.presidencia.gob.mx/

Papadópulos, J., \& Radakovich R. (2003). Estudio Comparado de Educación Superior y Género en América Latina y el Caribe. IESALC-Unión de Universidades de América Latina. Recuperado http://www.ses.unam.mx/curso2013/pdf/ Papadopulos2006.pdf

Secretaría de Educación Pública. (2007a). Programa de Becas para Adolescentes Embarazadas (DOF: 03-04-2006). Recuperado de http://www.promajoven.sep.gob.mx/

(2007b). Programa de Becas Fundación Azteca (DOF: 30/05/2008). Recuperado de http://www. fundacionazteca/fundacionazteca/plantel.shtml (2007c). Programa de Capacitación al Magisterio para Prevenir la Violencia contra las Mujeres (DOF: 29/12/2013 Acuerdo 712). Recuperado de http:// dof.gob.mx/nota_detalle.php? codigo $=5328399 \& \mathrm{f}$ echa $=29 / 12 / 20130$ 
(2007d). Programa de Formación Docente de Educación Media (DOF: 03-04-2008). Recuperado de http://www.profordems.sems.gob.mx

(2007e). Programa Sectorial de Educación 2007-2012 (DOF: 31-05-2007). Recuperado de http://sep_congreso.sep.gob.mx/prog_nacional/ prog_na.html

(2007f). Programa Nacional de Becas para la Educación Superior (DOF: 01/04/2004). Recuperado de http://pronabes.sep.gob.mx/index.html

(2007g). Programa Nacional de Becas para la Retención de Estudiantes de Educación Media Superior (DOF: 31/12/2008 Acuerdo 479). Recuperado de http://www.sep.gob.mx/es/sep1/becas_para_la_retencion_de_estudiantes_de_educacio
Secretaría de Desarrollo Social. (2009). Programa Oportunidades (DOF: 31/05/2007). Recuperado de http://www.oportunidades.gob.mx/TRANS/ f11_archivos/Dise \% C3\% B1o_del_Programa_ Oportunidades_120609.pdf

(2007). Programa de Estancias y Guarderías Infantiles para Madres Trabajadoras (DOF: 10/01/2007). Recuperado de http://www.sedesol. gob.mx/index/index.php?sec $=801579$

Tuirán, R., \& Salles, V. (1998). "Cambios demográficos y socioculturales: familias contemporáneas en México”. En Schmukler B. (coord). Familias y relaciones de género en transformación (pp 115120). México. 